\title{
ENTRE PRESENÇAS E AUSÊNCIAS: O CENTRO DE CURITIBA E A RUA XV DE NOVEMBRO
}

\author{
Lilian Stedile Ferri ${ }^{1}$ \\ Luiz Eduardo Fontoura Teixeira ${ }^{2}$
}

\section{Introdução}

O presente estudo visa a uma análise crítica acerca das problemáticas urbanas inerentes ao bairro Centro de Curitiba-PR nos dias atuais. Apesar do entendimento de que também as bordas dos bairros contíguos ao Centro apresentam dinâmicas urbanas características de área central, escolheu-se, aqui, a delimitação territorial do bairro para a explanação que se pretende desenvolver. A seguir (Figura 1), é possível visualizar o Centro de Curitiba e os bairros a ele limítrofes, conforme institucionalizados.

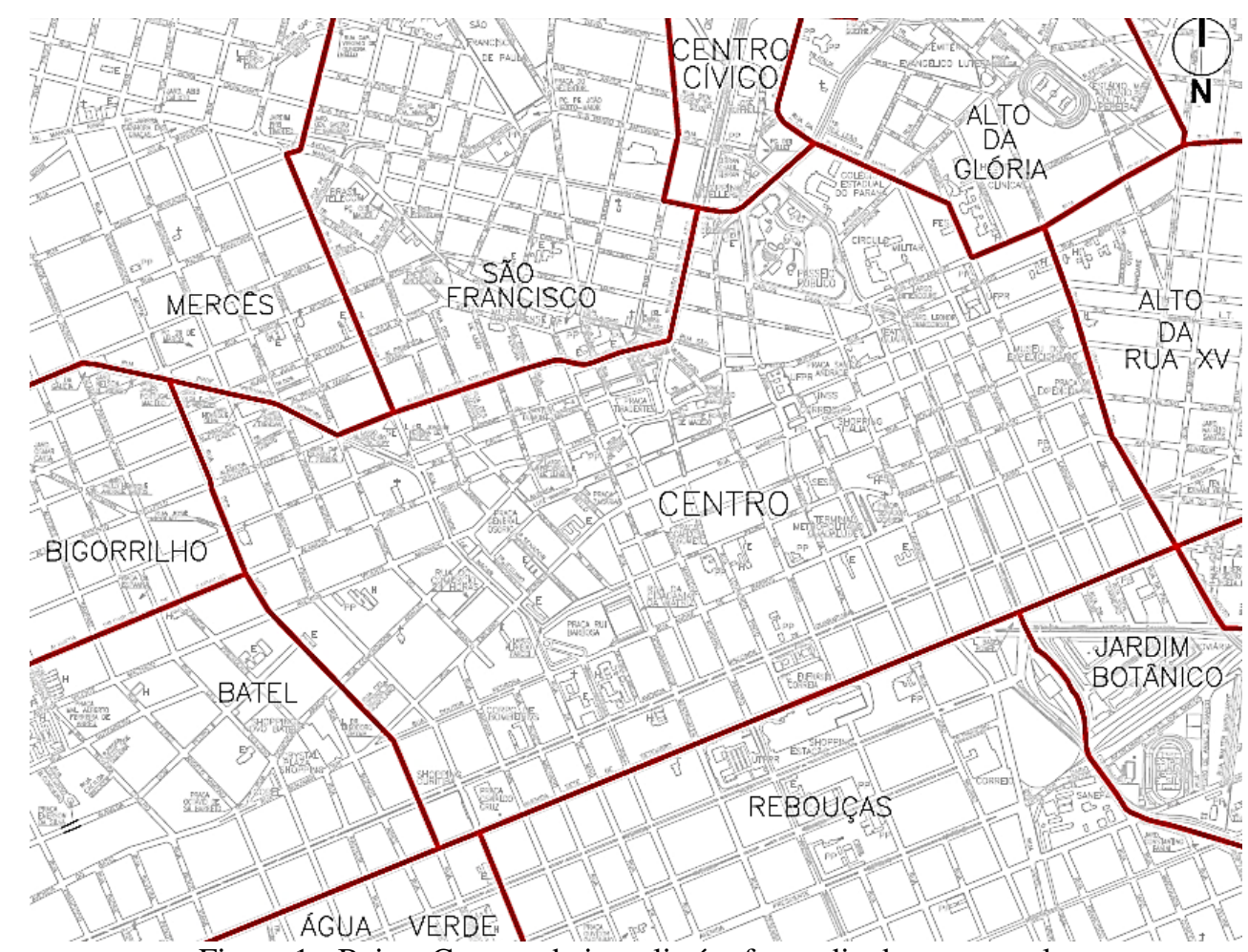

Figura 1 - Bairro Centro e bairros limítrofes - editado, sem escala.

Fonte: Instituto de Pesquisa e Planejamento Urbano de Curitiba, Ippuc, 2014

\footnotetext{
${ }^{1}$ Universidade Federal de Santa Catarina, Brasil.

${ }^{2}$ Universidade Federal de Santa Catarina, Brasil.
} 
Ao longo do tempo, as áreas centrais das grandes cidades brasileiras vivenciaram processos urbanos distintos, assim como "polarizaram ou ainda polarizam fluxos e funções que foram ou são determinantes na definição de seus significados cultural e simbólico e na consolidação da dinâmica e organização urbanas" (Brasil, 2011: 21). Devido à importância histórica que apresenta, o Centro de Curitiba, assim como a maioria dos centros das grandes cidades brasileiras, ocupou posição de destaque na evolução urbana local. Entretanto, nas últimas décadas, diversos desses centros têm sido confrontados com processos de negligência e abandono, em decorrência de distintos fatores. Acredita-se que um dos principais elementos responsáveis por essa situação seja o fortalecimento de um uso do solo monofuncional, alheio à necessidade de uma salutar diversidade urbana local.

\section{Os centros urbanos e o uso do solo}

Um dos maiores problemas encontrados nos centros urbanos, portanto, vincula-se à contínua perda de população moradora dessas áreas, devido, também, à criação de novas centralidades nas cidades, bem como à privatização de espaços - proliferação de shopping centers e condomínios residenciais fechados, por exemplo. É por isso que, em relação ao Centro de Curitiba, pode-se dizer que o enfraquecimento do uso residencial local, aliado ao fortalecimento do uso comercial e de serviços, contribui, sobremaneira, para a situação de vulnerabilidade vivenciada nos seus espaços de uso público. É devido a isso, principalmente, que é possível perceber que o bairro não apresenta a mesma dinâmica urbana em todos os horários e dias da semana, uma vez que seu uso do solo é, prioritariamente, comercial e de serviços. Nesse sentido, acredita-se que o uso do solo encontrado nessa área da cidade - vinculado a outras problemáticas, tais como o sistema local de espaços livres dominado pelas plataformas do transporte coletivo - seja um dos principais fatores responsáveis também pela situação de insegurança pública ali verificada.

Há diversas décadas, estudiosos do tema têm se debruçado sobre questões que abrangem a apropriação e a sociabilidade nos espaços públicos urbanos, e a urgente necessidade de recuperação da anterior multifuncionalidade dessas áreas, mediante a aplicação de soluções que propiciem a circulação e a permanência de pessoas nos espaços urbanos além do horário estritamente comercial, ou seja, em todos os horários e 
dias de semana. A ativista e jornalista americana Jacobs (2000), ainda em meados do século passado, já defendia a necessidade de um número suficiente de pessoas transitando pelas calçadas - o máximo de tempo possível - pois, de acordo com a autora, tal fato estimula que pessoas moradoras do entorno sintam-se atraídas a olhar o movimento existente, e, assim, contribuam para a segurança necessária nesses locais, conformando uma salutar sociabilidade vigiada. Talvez fosse pautada pelo senso de comunidade que a autora defendia tais preceitos, uma vez que acreditava que, quanto maior o número de contatos triviais entre as pessoas de uma área, tanto maior o grau de estabelecimento de uma rede de confiança e respeito entre as mesmas.

Contudo, é necessário mencionar, Jacobs (2000) também apontava para a importância de existir um número mínimo de estabelecimentos comerciais em uma rua, de maneira a propiciar a atração de pedestres nos trechos que não possuem espaços livres, por exemplo; tal fato corrobora a ideia da multiplicidade de usos nos espaços. Segundo a autora, deve-se lutar para que se impeça a destruição daquela que se apresenta como uma das principais características inerentes a uma formação urbana: a diversidade. Nesse sentido, as áreas urbanas regidas pelo princípio da diversidade tornam-se mais aprazíveis ao caminhar, bem como contribuem para a conformação de paisagens imprevisíveis, componentes de novas perspectivas. No entanto, em oposição, áreas compostas por usos únicos apresentam maiores probabilidades de se transformarem em bairros decadentes; para a autora, "a estrutura real das cidades consiste na combinação de usos; e nós nos aproximamos de seus segredos estruturais quando lidamos com as condições que geram a diversidade" (Jacobs, 2000: 417).

\section{Os espaços públicos e a sociabilidade urbana}

Partindo-se da vinculação da diversidade ao aspecto social, revela-se pertinente o ponto de vista de Frúgoli Jr. (2007: 54), para quem qualquer indivíduo pode ser considerado "um ponto privilegiado de cruzamento de vários círculos sociais, portanto, um polo de relações e tensões"; conforme o autor, o conceito de sociabilidade também está relacionado aos modos por meio dos quais a espécie humana organiza-se. A partir disso, conclui-se que a diversidade inerente a toda forma de aglomeração humana configura-se como um aspecto positivo e enriquecedor para a sociabilidade humana no 
espaço público urbano, pois possibilita o encontro e a agregação de diversidades individuais.

Todavia, nos dias atuais, a esfera pública, sempre tão fortemente demarcada em relação à privada, pode estar passando por um processo de diluição de fronteiras, uma vez que a vigilância existente nos mais variados âmbitos das sociedades contemporâneas revela a tendência de configuração de uma cidade construída de vidro transparente (Cortés, 2008). É assim que, hoje, os olhos humanos têm sido substituídos pelos olhos das novas tecnologias, que asseguram monitoramento e controle constantes por meio de aparatos de vigilância e conectividade. Esse fato é contrário àquele postulado por Jacobs (2000), para quem os olhos da rua, por si mesmos, já assegurariam a vigilância constante pelos seus moradores e usuários, garantindo, por conseguinte, a necessária segurança dos espaços públicos.

O modo de vida privatizante que temos vivenciado na contemporaneidade pode ser considerado, ainda, um novo modelo de apartheid urbano que, ao redor do mundo, está contribuindo significativamente para o enfraquecimento do espaço público acessível, bem como do tecido social e territorial da cidade (Cortés, 2008). Assim, conforme o autor, quando há uma progressiva utilização seletiva da cidade tomada por um espírito privatizante, pode ocorrer a consequente deterioração e abandono dos espaços públicos urbanos. Entretanto, é importante ressaltar que, diluídos ou não, o espaço público e o espaço privado continuam vinculados, e qualquer modificação em um dos dois acarretará, indubitavelmente, transformações também na estrutura do outro. Por isso, não são elementos antagônicos, mas que, por estarem inseridos em uma ordem de subordinação mútua, são complementares.

Contudo, ao longo da história humana, o caráter de cada uma dessas categorias sofreu profundas modificações. Em relação, por exemplo, à sociabilidade neles ocorrida, verifica-se que o espaço público esteve, geralmente, muito mais vinculado à figura masculina e ao mundo da liberdade, ao passo que, para as mulheres, era reservado o espaço seguro do lar, o espaço privado. Diante disso, entende-se espaço privado como aquele relacionado à esfera íntima e pessoal, comumente associado aos sentimentos e à intuição; enquanto que o espaço público, associado à eficácia, relacionase com a prática do discurso e do manifesto. Entretanto, de acordo com Cortés (2008), esse tipo de noção de público e privado também foi sendo alterada, gradualmente, no decorrer da história. 
Em se tratando da sociabilidade urbana, é também necessário apreender a complexidade do conceito de espaço público urbano. Para Leite (2007), um espaço que não contemple as distintas práticas de interação entre os agentes da sua construção social, é nada mais que um espaço urbano; da mesma maneira, a realização de tais interações, isentas de referência espacial, configura somente a esfera pública. Mediante essas afirmações, é possível dizer que o conceito de espaço público somente está atrelado às interfaces entre os conceitos de esfera pública (relacionada com a ação social) e espaço urbano (remetido à configuração espacial) quando abrange as "relações de reciprocidade causal entre a construção social do espaço e a espacialização das ações" (Leite, 2007: 198).

Diante do exposto, configura-se como uma das alternativas, vislumbradas nesse universo de diluição e inter-relação, propiciar a criação de espaços públicos que possam estar inseridos em transformações particulares, ou, então, espaços privados que possam ser utilizados de modo coletivo e solidário, como extensão do espaço público. Tais princípios podem ser aplicados em diferentes locais de encontro de pessoas que, mesmo possuindo caráter particular, podem adquirir feição pública, configurando-se como locais intermediários.

Assim, torna-se desejável haver um maior esforço no sentido de coletivizar determinados espaços privados para que possam ser, ao menos em parte, também de domínio público e partícipes da construção social da cidade. Nesse contexto, entra em cena o conceito de espaço social, que, para Castells (2012), é resultante da relação de identidade entre um grupo social e o espaço em si. É quando aquilo que é meramente figurativo fica relegado a um segundo plano, dando voz aos procedimentos realizados, ou seja, às vivências de quem daquele espaço se apropria. Permite-se dizer, portanto, que não se trata de um espaço de representação, mas, de um espaço de apropriação.

\section{O fortalecimento da habitação no Centro: uma alternativa possível}

Conforme já mencionado, além de outros fatores, o enfraquecimento de um centro urbano pode estar diretamente relacionado à criação de novas centralidades na cidade, seja devido a uma contínua e ininterrupta expansão do tecido urbano para áreas periféricas - visando-se à implantação de moradias destinadas à baixa renda para esses territórios mais precários e distantes - ou devido à expansão das ocupações irregulares 
(Meyer, 2001). Todavia, a criação de novas centralidades, pressupõe a implantação de novas redes de infraestrutura, ao contrário do que aconteceria se o direcionamento do uso residencial fosse feito para as áreas centrais, portadoras de uma infraestrutura urbana consolidada que, em grande parte, revela-se ociosa fora do horário comercial. Assim, propiciar a implantação de moradias nessas áreas - especialmente habitação de interesse social - configura-se como um dos meios de diminuir a expansão horizontal do tecido urbano em direção às áreas ambientalmente frágeis, além de promover o cumprimento da função social da terra urbana.

Porém, não se pode negligenciar a existência de certo preconceito generalizado em incluir famílias de baixa renda em áreas centrais brasileiras. Os discursos contrários à inserção da habitação social nessas áreas são pautados na possibilidade de contenção da valorização imobiliária local, sendo, portanto, um ponto negativo; contudo, há que se ponderar que frear a especulação gerada por essa valorização é uma tarefa necessária para agir no caminho da justiça social. E, apesar de existir determinado consenso de que políticas dessa natureza, juntamente com importantes programas habitacionais já implementados no país, não puderam reverter totalmente a tendência de crescimento de ocupações irregulares e periferização das cidades, tais iniciativas têm se mostrado meios importantes de decréscimo da intensidade desses processos, contribuindo para que novos quadros possam ser vislumbrados.

Por outro lado, existe, também, número significativo da massa trabalhadora que já reside nas áreas centrais das grandes cidades - e Curitiba não foge à regra. Tal população habita, geralmente, edificações deterioradas, provisórias e improvisadas, em que não é preciso apresentar comprovante de renda (alternativa viável a trabalhadores informais) - sendo possível permanecer mediante o pagamento de aluguéis mensais decorrentes do valor ao qual aquele imóvel está subordinado, ou seja, ao preço da terra.

Para Ribeiro (1997: 49), o valor ou preço da terra é apontado como o "mecanismo econômico responsável pela constituição do espaço urbano e pela segregação social na cidade". O autor afirma que, apesar de a propriedade privada ser considerada um dos principais males das cidades capitalistas, são os modos de utilização do espaço urbano que conferem valor à propriedade da terra. De acordo com Maricato (2001), a terra urbana pode ser considerada aquela porção de terra composta por infraestrutura e serviços, ou seja, apta a receber moradias - considerando-se que tais investimentos geram renda aos proprietários fundiários e imobiliários, a espacialização de tais imóveis 
na cidade torna-se fator determinante. É assim que as ocupações irregulares, como loteamentos clandestinos e favelas, compõem quadros de exclusão territorial vinculados à valoração da terra urbana.

Em relação, especificamente, ao Centro de Curitiba, o Poder Público tem se mostrando conivente com a urgência de trazer, novamente, moradores ao bairro, de modo a propiciar presenças constantes em seus espaços urbanos. Todavia, apesar de existir um esforço, por sua parte, de demonstrar o real retorno de habitantes à área, dados disponibilizados pelo próprio Instituto de Pesquisa e Planejamento Urbano de Curitiba (Ippuc), órgão municipal, confirmam algo que não condiz com tudo o que tem sido apregoado. É possível visualizar nas tabelas abaixo (Figuras 2 a 4) - embasadas em censos demográficos realizados da década de 1970 ao ano de 2010 - que, se na década de 1970 o Centro era o bairro mais populoso do município, nas décadas seguintes sua população decresceu em comparação com as de outros bairros, sendo relegado a posições mais baixas. Ademais, a partir de meados dos anos de 1990, o bairro Centro já desaparece do ranking dos dez bairros mais populosos da capital paranaense.

Segundo o último censo realizado, de 2010, o Centro de Curitiba possui 37.283 habitantes - número similar àquele apresentado nos anos 1970, que era de 37.086 habitantes - mas que, hoje, encontra-se bem abaixo do décimo colocado da lista, o bairro Pinheirinho, que apresenta 50.401 habitantes (Ippuc, 2014).

\begin{tabular}{|c|c|c|c|c|}
\hline \multirow{2}{*}{ Posição } & \multicolumn{2}{|c|}{1970} & \multicolumn{2}{|c|}{1980} \\
\hline & Bairros & População & Bairros & População \\
\hline $1^{\circ}$ & Centro & 37.086 & Boqueirão & 52.668 \\
\hline $2^{\circ}$ & Boqueirão & 27.003 & Cidade Industrial & 45.904 \\
\hline $3^{\circ}$ & Portão & 25.749 & Cajuru & 45.425 \\
\hline $4^{\circ}$ & Água Verde & 25.114 & Centro & 42.371 \\
\hline $5^{\circ}$ & Cidade industrial & 21.973 & Xaxim & 38.529 \\
\hline $6^{\circ}$ & Novo Mundo & 20.768 & Novo Mundo & 35.238 \\
\hline $7^{\circ}$ & Rebouças & 20.058 & Portão & 33.511 \\
\hline $8^{\circ}$ & Uberaba & 18.211 & Capão Raso & 32.757 \\
\hline $9^{\circ}$ & Capäo Raso & 18.071 & Pinheirinho & 32.139 \\
\hline $10^{\circ}$ & Mercês & 17.413 & Água Verde & 31.979 \\
\hline
\end{tabular}




\begin{tabular}{|c|c|c|c|c|}
\hline \multirow{2}{*}{ Posiçäo } & \multicolumn{2}{|c|}{1991} & \multicolumn{2}{|c|}{1996} \\
\cline { 2 - 4 } & Bairros & População & Bairros & População \\
\hline $1^{\circ}$ & Cidade Industrial & 116.001 & Cidade Industrial & 150.985 \\
$2^{\circ}$ & Cajuru & 76.384 & Sítio Cercado & 89.034 \\
$3^{\circ}$ & Boqueirão & 64.086 & Cajuru & 84.286 \\
$4^{\circ}$ & Sitio Cercado & 52.498 & Boqueirão & 66.462 \\
$5^{\circ}$ & Xaxim & 46.754 & Xaxim & 50.237 \\
$6^{\circ}$ & Água Verde & 45.438 & Água Verde & 49.863 \\
$7^{\circ}$ & Pinheirinho & 44.070 & Pinheirinho & 48.036 \\
$8^{\circ}$ & Alto Boqueirão & 43.280 & Alto Boqueirão & 47.619 \\
$9^{\circ}$ & Novo Mundo & 38.188 & Uberaba & 45.676 \\
$1^{\circ}$ & Centro & 37.003 & Novo Mundo & 40.770 \\
\hline
\end{tabular}

\begin{tabular}{|c|c|c|c|c|}
\hline \multirow{2}{*}{ Posição } & \multicolumn{2}{|c|}{2000} & \multicolumn{2}{c|}{2010} \\
\cline { 2 - 5 } & Bairros & População & Bairros & Populaçäo \\
\hline $1^{\circ}$ & Cidade Industrial & 157.461 & Cidade Industrial & 172.822 \\
$2^{\circ}$ & Sitio Cercado & 102.410 & Sitio Cercado & 115.525 \\
$3^{\circ}$ & Cajuru & 89.784 & Cajuru & 96.200 \\
$4^{\circ}$ & Boqueirão & 68.495 & Boqueirão & 73.178 \\
$5^{\circ}$ & Uberaba & 60.338 & Uberaba & 72.056 \\
$6^{\circ}$ & Xaxim & 54.691 & Xaxim & 57.182 \\
$7^{\circ}$ & Aito Boqueirão & 51.155 & Alto Boqueirão & 53.671 \\
$8^{\circ}$ & Água Verde & 49.866 & Tatuquara & 52.780 \\
$9^{\circ}$ & Pinheirinho & 49.689 & Água Verde & 51.425 \\
$10^{\circ}$ & Novo Mundo & 42.999 & Pinheirinho & 50.401 \\
\hline
\end{tabular}

Figuras 2 a 4: Dez bairros mais populosos de Curitiba - 1970 a 2010 (editado). Fonte: Instituto de Pesquisa e Planejamento Urbano de Curitiba, Ippuc, 2014.

Além disso, destaca-se outra peculiaridade em relação à questão habitacional no Centro de Curitiba: de acordo com Ultramari et al. (2014), comparando-se as pirâmides etárias de outros bairros com a do bairro Centro, percebe-se que a pirâmide deste revelase mais estreita em sua base. Isso indica, portanto, a existência de um menor número de crianças no bairro; porém, percebe-se que a faixa reservada aos jovens entre 19 e 29 anos é bem maior que as encontradas nas pirâmides dos outros bairros da cidade. Contudo, em termos gerais, salienta-se que a maioria desses jovens não mora com seus respectivos pais - não sendo, portanto, partes constituintes de um núcleo familiar que reside no mesmo local - visto que, para que isso ocorresse, a proporção de adultos moradora do bairro deveria ser muito maior do que a existente.

Conforme os autores, ao que tudo indica, a maioria desses jovens reside somente durante alguns anos no Centro - ao longo de sua formação acadêmica e/ou início da vida profissional - sendo que, nos anos subsequentes, quando iniciam a constituição de suas 
próprias famílias, os mesmos se mudam para outros bairros, contribuindo para a baixa natalidade verificada na área central.

Entretanto, se, por um lado, o número de crianças residindo no Centro é baixo, por outro, a quantidade de idosos - mulheres viúvas, principalmente - é bastante significativo e relevante quando também comparado ao restante da cidade (Ultramari et al., 2014). É por isso que se entende como de grande urgência que as ações públicas pensadas para essa área da cidade considerem a parcela da população já moradora do bairro, a qual faz uso massivo do sistema de transporte coletivo local e adequa-se bem aos imóveis mais antigos ali existentes, além de contribuírem com a dinamicidade urbana local.

\footnotetext{
Mas são eles [jovens e idosos] que ocupam essa parte da cidade e devemos fazer todo o possível para mantê-los atraídos pelo Centro, com espaço público de qualidade, investindo em áreas livres e calçadas bem cuidadas (com acessibilidade para idosos), serviços públicos de referência e redução da pressão automobilística, pois afeta uma população que usa menos o carro (Ultramari et al., 2014: 26).
}

Diante do exposto, pontua-se, aqui, que não se objetiva, no presente estudo, propor alternativas para a gestão habitacional do bairro; entretanto, visa-se à apresentação de alguns preceitos gerais plausíveis de serem aplicados em áreas portadoras de infraestrutura urbana consolidada e edificações subutilizadas, como é o caso, especificamente, do recorte escolhido para análise - o calçadão da Rua XV de Novembro e seu patrimônio edificado subutilizado, a seguir apresentados.

\section{O calçadão da Rua XV de Novembro: problemas e potencialidades}

Assim, para fortalecer a análise e vislumbrar novas potencialidades de mudanças positivas nesse contexto, escolheu-se para estudo o calçadão da Rua XV de Novembro ou Rua das Flores, assim conhecido esse trecho. Localizada no Centro de Curitiba, essa parte da rua foi transformada em espaço destinado exclusivamente para pedestres no ano de 1972 (Figura 5), configurando-se como experiência inovadora no país e, portanto, como modelo para diversas outras cidades desde então (Patrimônio Cultural, 2014). 


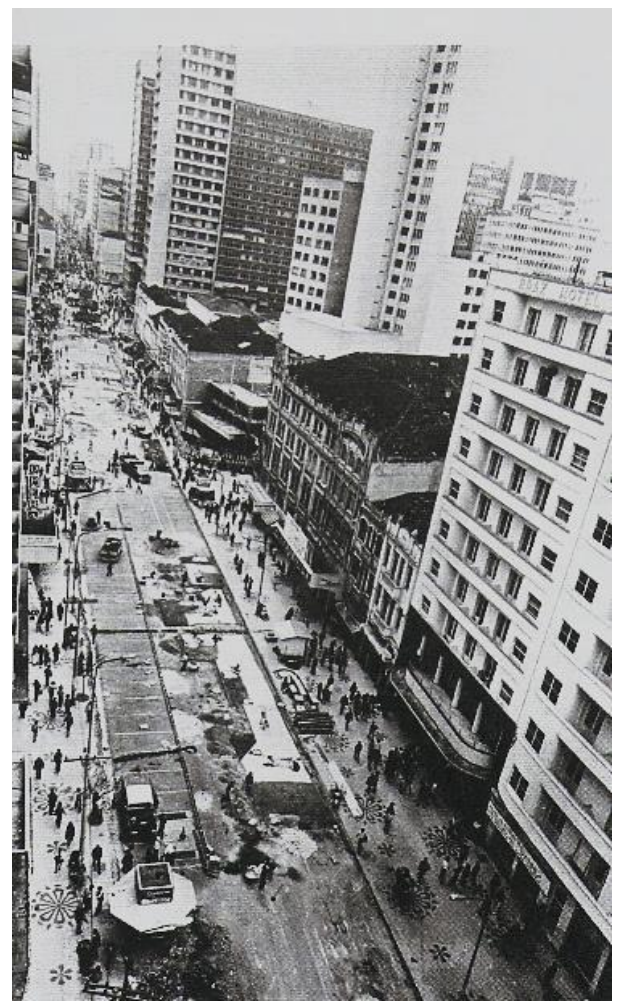

Figura 5 - Obra de execução do calçadão da Rua XV de Novembro, 1972. Fonte: Ciffoni; Sutil; Baracho, 2006.

Executado durante a primeira gestão do arquiteto e urbanista Jaime Lerner à frente da Prefeitura de Curitiba, tal ação cunhou-se como exemplo de uma intervenção projetual de priorização do pedestre e do espaço público urbano como aquele pensado exclusivamente para o homem e suas relações sociais construídas em pequena escala. Apesar de, na época, proliferarem as críticas contrárias à intervenção - principalmente advindas dos comerciantes locais - há que se dizer que a iniciativa revelou-se um marco em um novo modo de conceber o espaço urbano.

Ainda me lembro de que, ao divulgar o projeto, a reação dos comerciantes foi contrária e muito forte. Sabíamos que a ideia era de difícil execução, pois a obra poderia ser interrompida por demandas judiciais. Era imperioso que o trabalho fosse rápido, muito rápido. [...] consegui um acordo para um prazo de 72 horas. Começaríamos numa sexta-feira à noite e entregaríamos a obra à população na segunda-feira à noite. Caso o povo não aprovasse a mudança, sempre poderíamos restabelecer o que havia antes. Mas era necessário que a população visse a obra completa. E assim foi feito. No dia seguinte à inauguração, um dos comerciantes que encabeçavam um abaixo-assinado contra o projeto apresentou-me um novo pedido: que as obras continuassem e abrangessem mais regiões (Lerner, 2005: 104). 
Porém, aquilo que, em seu início, configurou-se como iniciativa que trouxe aspectos positivos ao contexto local, também fortaleceu, ainda mais, o uso comercial naquela área; tal fato perdura ainda nos dias atuais, a exemplo do que ocorre no restante do bairro. Desse modo, verifica-se que o locus do calçadão da Rua XV de Novembro, apesar das peculiaridades urbanas a ele inerentes, apresenta a mesma problemática de esvaziamento no horário não-comercial presente em praticamente todo o bairro.

Apesar disso, esse trecho da rua tem sido escolhido, há diversos anos, como cenário para a realização de relevantes apresentações artísticas além do horário comercial, e que atraem pessoas advindas de diferentes bairros de Curitiba, bem como dos municípios vizinhos, para assistir aos espetáculos. As apresentações realizadas compõem, sobretudo, as festividades de final de ano, como a Galeria de Luz, que tem atraído uma multidão de pessoas para assistir aos espetáculos teatrais de luz e de som, além de compor um cenário com estruturas metálicas iluminadas que ali permanecem durante os dias de apresentação. Iniciativas com esse caráter, apesar de promoverem a atração de pessoas somente nos horários a elas inerentes, mostram a grande relevância de um espaço público urbano como palco de manifestações, atividades e encontro de diversidades individuais.

Por meio de intervenções como essas, visualiza-se que, para que um espaço urbano se transforme em um espaço verdadeiramente social, é imprescindível o elemento humano, que confere ao espaço uma dinamicidade inerente. Contudo, para que a multidão não se dissipe quando os espetáculos artísticos terminam, mas continue a participar daquele outro espetáculo, ainda mais necessário - o espetáculo cotidiano das ruas - é necessária a configuração de espaços que também sejam conformados, principalmente, pelas tão salutares presenças de moradores e visitantes mais constantes.

Além desses aspectos, bem como da configuração urbana diferenciada em relação à maioria dos espaços públicos do bairro e da cidade, a importância dessa área do Centro de Curitiba também se deve ao fato de possuir um casario histórico que compõe uma paisagem urbana tombada em nível estadual, no ano de 1974 (Patrimônio Cultural, 2014). Resultado de legislações municipais do início do século XX que restringiram as construções de madeira na área central da cidade, bem como da regulamentação de gabarito - dois a três pavimentos - para as novas edificações em alvenaria (Figura 6), o casario eclético existente no calçadão da Rua XV de Novembro passou a conformar um dos mais significativos conjuntos arquitetônicos da cidade (Celinski, 2013). 


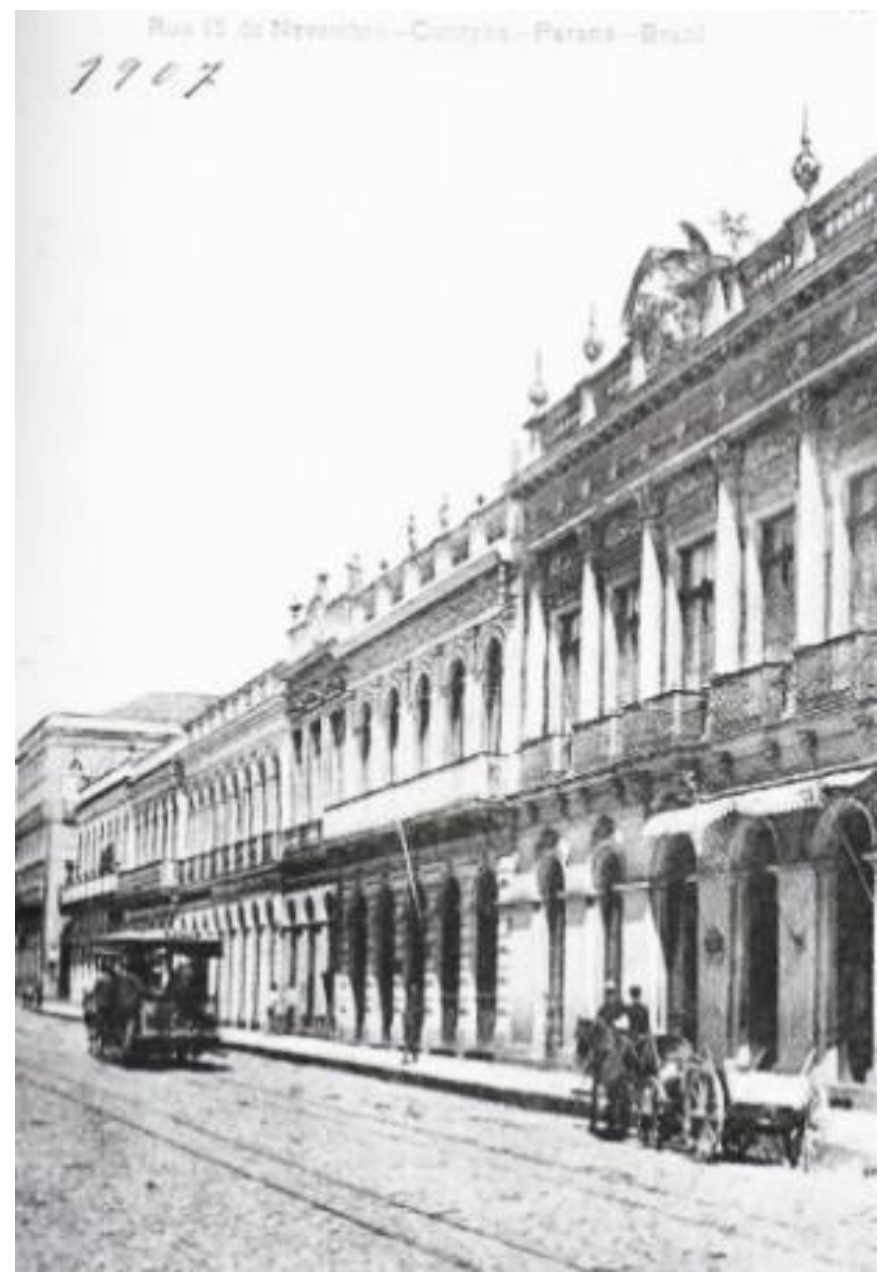

Figura 6 - Casario da Rua XV de Novembro, 1907. Fonte: Ciffoni; Sutil; Baracho, 2006.

Todavia, atualmente, tem sido constatada uma situação preocupante relacionada aos usos desses imóveis localizados no calçadão - cuja extensão contempla o trecho entre a Praça General Osório à Rua Presidente Faria: significativa parcela dessas edificações encontra-se abandonada ou subutilizada (Figura 7), ou seja, possuem seus pavimentos térreos ocupados, mas os superiores permanecem vazios ou, algumas vezes, destinados somente a depósitos dos estabelecimentos comerciais alocados nos pavimentos térreos. 


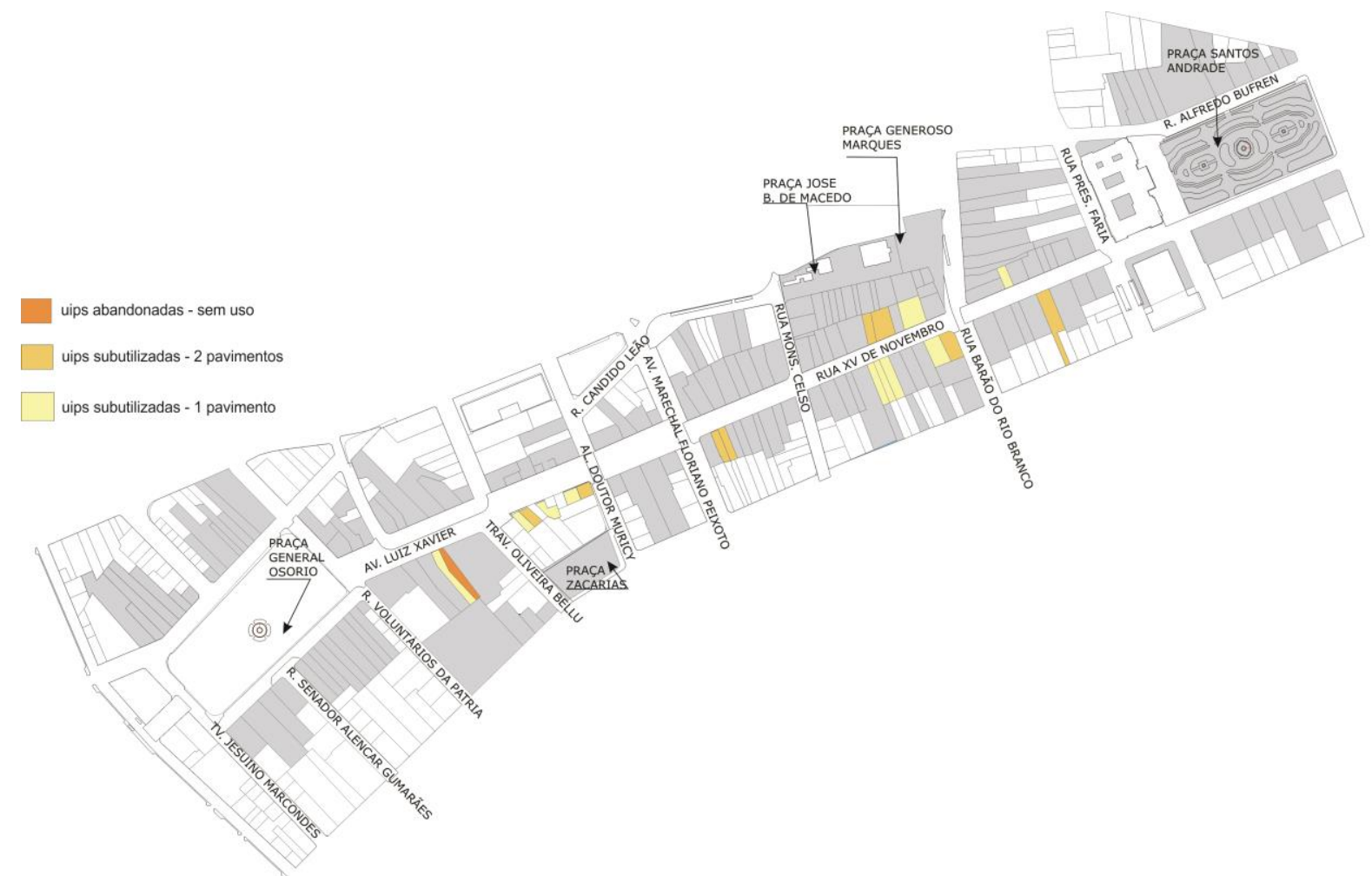

Figura 7 - Imóveis subutilizados e abandonados no trecho de calçadão da Rua XV de Novembro. Fonte: Setor de Patrimônio Histórico, Instituto de Pesquisa e Planejamento Urbano de Curitiba, 2013.

Além dessa problemática, há, ainda, aquela relacionada à preservação desse patrimônio: verifica-se que, apesar do tombamento em paisagem e do tombamento individual - em nível estadual - de algumas edificações, diversas delas possuem sua preservação assegurada mediante a prerrogativa de serem também Unidades de Interesse de Preservação (UIP's), cuja proteção é em nível municipal. Contudo, constata-se que, embora as fachadas desse casario estejam, de modo geral, bem conservadas, não se pode dizer o mesmo de vários de seus espaços internos, cuja precariedade encontrada denota a vulnerabilidade da legislação a que estão submetidos.

Nas figuras a seguir (Figuras 8 a 15), resultados de levantamentos realizados, em 2013, pelo Setor de Patrimônio Histórico do Instituto de Pesquisa e Planejamento Urbano de Curitiba (Ippuc), é possível visualizar o estado de subutilização ou ociosidade em que se encontram os interiores de diversas edificações, as quais apresentam, inclusive, degradação na infraestrutura e precariedade nas instalações. 

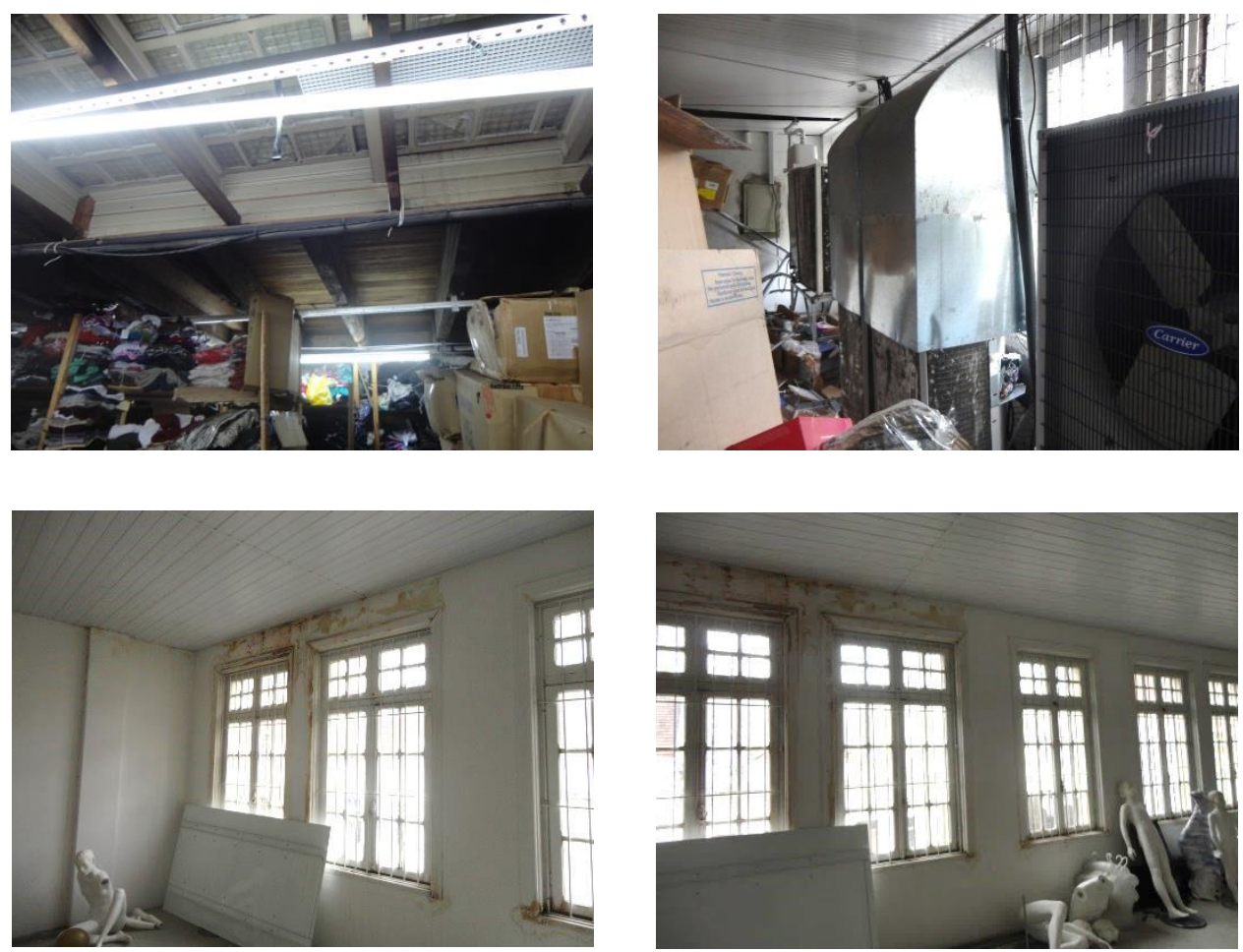

Figuras 8 a 11 - Interiores de imóveis localizados no calçadão da Rua XV de Novembro.

Fonte: Setor de Patrimônio Histórico, Instituto de Pesquisa e Planejamento Urbano de Curitiba, 2013.
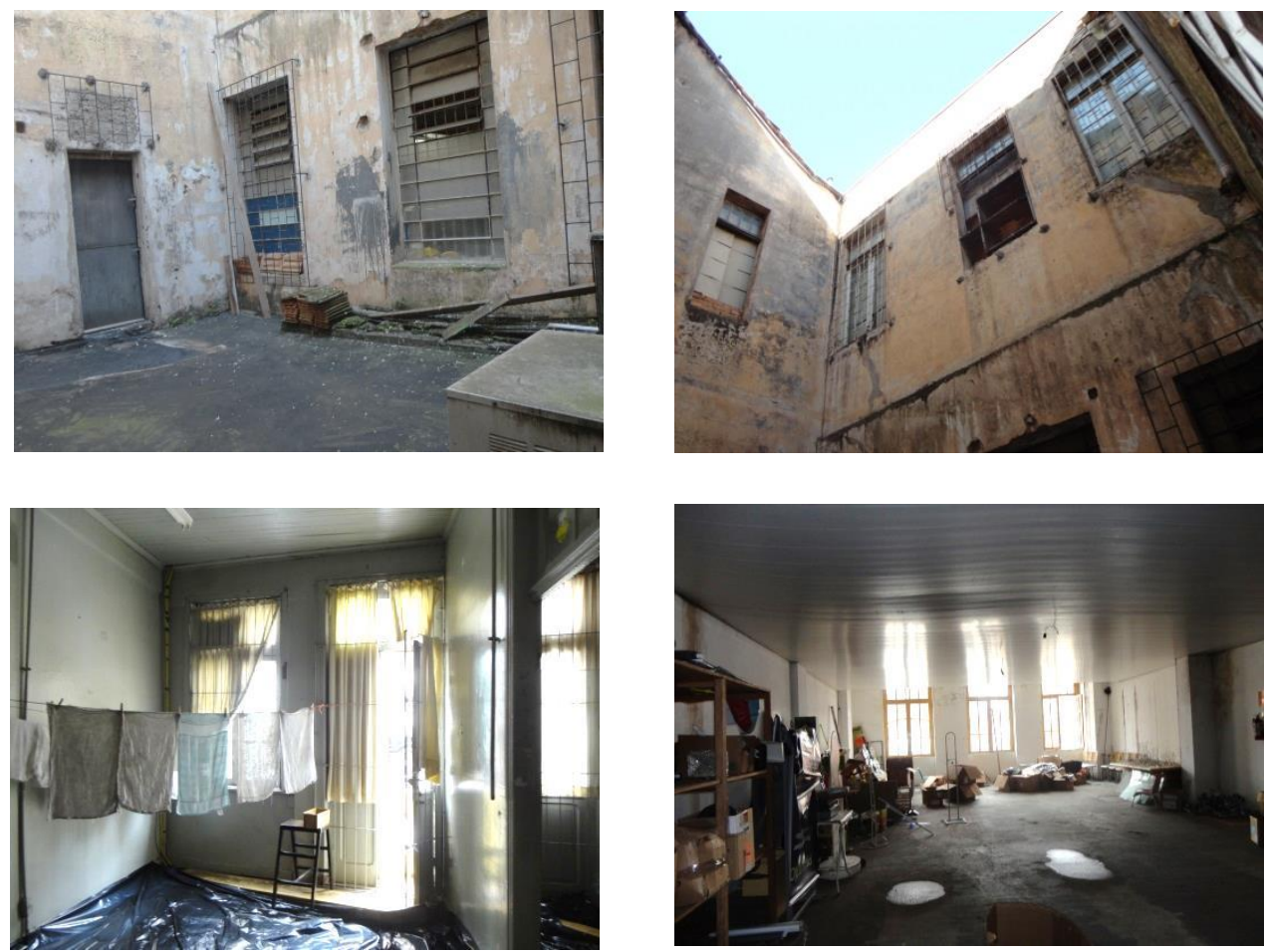

Figuras 12 a 15 - Interiores de imóveis localizados no calçadão da Rua XV de Novembro.

Fonte: Setor de Patrimônio Histórico, Instituto de Pesquisa e Planejamento Urbano de Curitiba, 2013. 
Contudo, para atenuar e resolver essa situação, pode-se espelhar em projetos bemsucedidos de conservação e reintegração do patrimônio construído à vida ativa da sociedade local. Apesar de ainda existirem inúmeras iniciativas destinadas, prioritariamente, ao turista ou ao consumidor eventual, há, por outro lado, certo reconhecimento do caráter limitador de ações voltadas somente a esse segmento da economia. Há que se pensar, ainda, nos fatores negativos advindos de uma superlotação de pessoas visitando essas áreas históricas, resultando em uma infraestrutura que, não raro, vê-se excedida em seus limites (Silva; Oliveira; Borges, 2011).

É devido a isso que, para os autores, configura-se como um dos quadros alternativos a uma possível museificação e espetacularização urbana, a gestão dos bens patrimoniais locais associados aos circuitos ativos da sociedade, ou seja, reintegrados às necessidades atuais da comunidade local e adequados funcionalmente para atividades básicas, como moradia, espaços de trabalho, de educação e de lazer.

O patrimônio das (e nas) cidades deixou de seguir a política da pedra e cal [...] para congregar o ambiente urbano em conjunto e em suas múltiplas manifestações, abarcando ruas, edifícios, casas, áreas verdes, assim como práticas culturais, hábitos e formas de apropriação e ressignificação do espaço (Silva; Oliveira; Borges, 2011: 73).

Em relação, especificamente, ao uso habitacional, é importante perceber que a demanda por moradias é algo inerente ao processo de conformação, e crescimento, das cidades - e assim continuará, uma vez que um abrigo físico é, e, provavelmente, sempre será humanamente necessário. Portanto, pode-se dizer que tal alternativa encontra-se na esteira dos princípios de retorno da multifuncionalidade a essas áreas, uma vez que, além de contribuir para a efetiva utilização de um imóvel, garante a sua perpetuação enquanto objeto dotado de memória e significado; é, portanto, um modo de resguardá-lo frente a um possível esquecimento.

Conforme Jeudy (2005: 15), “a conservação patrimonial se encarrega do depósito das lembranças e nos libera do peso das responsabilidades infligidas à memória". Todavia, nesse contexto, surge a indagação de que se ações dessa natureza, empreendidas em demasia, não poderiam causar, também, uma demasiada tranquilidade na memória coletiva dos povos - os quais, na sociedade contemporânea ocidental, sobretudo, arcam com o peso da responsabilidade moral de nada esquecer. Segundo o 
autor, para que exista a prática de reconhecimento do patrimônio existente, é necessário que a sociedade olhe para o que já produziu e que considere os elementos resultantes desse processo como "reflexos inteligíveis de sua história, de sua cultura", ou seja, que tal sociedade reconheça-se como espelho dela mesma (Jeudy, 2005: 19).

É por isso que, em casos como esse, torna-se imprescindível considerar a integração dos edifícios às exigências da vida contemporânea - trata-se de sua atualização funcional. Entretanto, de acordo com Choay (2001), reintegrar uma edificação que se encontra ociosa a um novo uso corresponde a um modo audacioso de valorização daquele patrimônio - essa afirmação está imbuída da ideia de que a opção de expor, novamente, a edificação a um uso pode contribuir para o seu próprio desgaste. É devido a isso que se revela necessário considerar a materialidade existente aliada a uma predeterminação do fluxo de usuários do local. A autora é categórica em afirmar que a conservação dos centros e bairros mais antigos somente será possível se a nova destinação a eles outorgada ocorrer de modo compatível com suas dimensões e morfologia existente.

A integração dos conjuntos urbanos históricos à vida contemporânea foi trazida à cena, em nível internacional, a partir dos anos de 1970, principalmente. Em 1976, foi adotada pela Unesco, em Nairóbi, a Recomendação relativa à proteção dos conjuntos históricos e tradicionais e ao seu papel na vida contemporânea, que, na visão de Choay (2001: 223), ainda se configura como a mais completa argumentação em favor de um tratamento não museal desses conjuntos. Além disso, admite a autora, conservar de modo vivo os conjuntos mais antigos de nossas cidades - ou seja, integrá-los ao cotidiano contemporâneo - corresponde a um modo de lutar "não apenas pela proteção de particularismos étnicos e locais, mas também contra o processo planetário de banalização e estandardização das sociedades e de seu meio" (Choay, 2001: 223).

Posto isso, é também relevante trazer à luz a discussão a respeito do acesso aos bens patrimoniais pelas distintas parcelas da população, uma vez que se sabe que as leis de salvaguarda e defesa do patrimônio construído acabaram, em grande parte dos casos, "provocando a expropriação cultural da maior parcela da população, que não se viu reconhecida nos majestosos exemplares da arquitetura pública ou religiosa” (Funari; Pelegrini, 2009: 57). Contudo, diversos são os exemplos, em nível internacional, de iniciativas de defesa do patrimônio construído associadas a políticas habitacionais, apresentando-se, assim, como um dos meios de se atrelar o patrimônio existente às 
dinâmicas contemporâneas da cidade. Além disso, é uma das maneiras de propiciar maior proximidade do patrimônio edificado com toda a população, de modo que, além de visto, o mesmo possa ser vivenciado como algo pertencente à identidade de seu povo.

A busca pela preservação dessa identidade caminha na contramão dos processos de globalização que se baseiam em iniciativas homogeneizadoras de edificações e paisagens; em suma, contrapõem-se àquelas iniciativas pautadas por discursos pósmodernos. Discursos em que, sobretudo, o patrimônio é apropriado somente para configuração de cenários destinados a consumidores de lugares, alinhando-se a um contexto resultado da aliança entre o Estado e os interesses privados de modo a "preservar o patrimônio histórico, num processo marcado pela formulação de políticas preservacionistas a partir da perspectiva do mercado" (Botelho, 2006: 49). É por isso que, conforme Funari e Pelegrini (2009: 59-60):

As políticas preservacionistas adotadas na América Latina apostam, cada vez mais, no envolvimento das comunidades e em iniciativas integradas entre o público e o privado. Mas a globalização e as inovações tecnológicas da contemporaneidade, somadas ao amálgama cultural incorporado à sociedade latino-americana, continuam suscitando muitas contendas a serem superadas.

Uma vez mais, atesta Jeudy (2005), o excesso de exibição ou de teatralização dos vestígios patrimoniais conservados pode suscitar posições contrárias ao patrimônio que foi preservado - deve-se entender que o passado deve ser conservado até o limite em que seu poder de rememoração não anule o presente. É nesse sentido que iniciativas de reabilitação de áreas urbanas alicerçadas em ações de pura estetização do patrimônio edificado conferem ares de espetáculo à esfera patrimonial. Trata-se de ações voltadas, principalmente, ao turista, bem como aos lucros que o consumo a ele vinculados serão propiciados; o habitante local passa a ser tratado como mero coadjuvante de um espetáculo em que o autor principal - o patrimônio arquitetônico - ganha roupagem nova, com ares de festa.

Nesse tipo de contexto, entram em cena as iniciativas responsáveis pela pura estetização do espaço urbano em seu nível mais elevado, tornando-o, diversas vezes, mero pastiche de outros lugares que passaram por experiências semelhantes. Logo, revela-se importante não negligenciar as peculiaridades locais; nas palavras de Castells (2012: 19), "refletir sobre a reabilitação de centros históricos, de bairros ou ruas na 
cidade contemporânea exige assumir o pressuposto sobre a cidade enquanto construção social".

É necessário recuperar as dimensões locais de produção do espaço urbano para compreender como se produziram suas velhas e novas centralidades. A partir daí, é possível compreender a produção social dos espaços tidos como degradados, que justificam as estratégias de intervenção de grande escala. Essas estratégias, por sua vez, são resgatadas e remodeladas pelas populações locais, que se reapropriam do espaço "revitalizado" de diversas formas e através de diversos usos (Botelho, 2006: $50)$.

Assim, conforme dito, é necessário atentar para a população já moradora do bairro, bem como priorizar iniciativas de atração de habitantes pertencentes às distintas camadas da população. Do contrário, adentrando-se em processos de mera estetização urbana ou do tratamento da cidade como pura mercadoria, a valorização imobiliária do local pode contribuir com uma consequente gentrificação urbana. Em impasses dessa natureza, quando o valor simbólico do objeto e o seu valor de mercado sobrepõem-se, é que a gestão patrimonial deve trabalhar com afinco, lutando para que aquele valor simbólico não seja, posteriormente, sobrepujado pelo mercadológico. Uma vez que é, portanto, também por meio de seu patrimônio edificado, produto materializado de um saber acumulado ao longo do tempo, que a sociedade pode se enxergar tal qual como ela é, ou, um dia foi.

\section{Considerações finais}

Conforme exposto, os centros urbanos das grandes cidades têm apresentado, atualmente, situações díspares e contraditórias. Se, por um lado, são dotados de uma infraestrutura urbana consolidada ao longo do tempo, por outro, não têm se mostrado capazes de atrair, suficientemente, significativas parcelas da população para neles residirem. Tal fato revela-se de grande preocupação, visto que são as pessoas moradoras de uma área que configuram as presenças mais constantes em seus espaços públicos urbanos, cada vez mais negligenciados em nome de uma vida privatizante e segregadora. O resultado disso é uma área composta por presenças humanas apenas em determinados períodos, sendo que, aos demais, relega-se somente as ausências de quem ali poderia ter permanecido. 
Em se tratando do bairro Centro de Curitiba, a situação não é diversa: apesar de ser uma área que ainda exerce atração sobre determinadas faixas etárias da população para ali residir - jovens universitários e idosos, sobretudo - a mesma vem sofrendo com a deterioração de diversos de seus espaços de uso público, visto que a ausência de um número suficiente de habitantes acarreta, consequentemente, uma maior insegurança pública e abandono. Nesse sentido, e apoiando-se em autores advindos de diferentes áreas do conhecimento, buscou-se explanar e clarificar tal situação vivenciada, hoje, nesse bairro da capital paranaense, de modo a trazer à luz questionamentos que possam se tornar propulsores de novas ideias e perspectivas para essa tão emblemática área da cidade.

\section{Referências}

BOTELHO, Tarcísio R. A revitalização da região central de Fortaleza (CE): novos usos dos espaços públicos da cidade. In: FRÚGOLI JR., Heitor; ANDRADE, Luciana Teixeira de; PEIXOTO, Fernanda Arêas (Org.). As cidades e seus agentes: práticas e representações. Belo Horizonte: PUC Minas/Edusp, 2006.

BRASIL. Ministério das Cidades. Instituto do Patrimônio Histórico e Artístico Nacional. Implementação de ações em áreas urbanas centrais e cidades históricas: manual de orientação. Brasília-DF: IPHAN: Ministério das Cidades, 2011.

CASTELLS, Alicia Norma Gonzáles de. Reabilitações urbanas na cidade contemporânea: entre as formas de fazer a cidade e as formas de fazer na cidade. In: CASTELLS, Alicia Norma Gonzáles de; NARDI, Letícia (Org.). Patrimônio cultural e cidade contemporânea. Florianópolis: Editora da UFSC, 2012.

CELINSKI, Camila M. O inventário como instrumento de proteção do patrimônio cultural em Curitiba. In: $3^{\circ}$ SEMINÁRIO IBERO-AMERICANO ARQUITETURA E DOCUMENTAÇÃO, 2013, Belo Horizonte, MG.

CHOAY, Françoise. A alegoria do patrimônio. São Paulo: Estação Liberdade: Editora UNESP, 2001.

CIFFONI, Ana Lúcia; SUTIL, Marcelo S.; BARACHO, Maria Luiza G. (Org.). Centro histórico: espaços do passado e do presente. Curitiba: Fundação Cultural de Curitiba, v. 30, n. 130, mar., 2006.

CORTÉS, José Miguel. Políticas do espaço. Arquitetura, gênero e controle social. São Paulo: Senac SP, 2008.

FRÚGOLI JÚNIOR, Heitor. Sociabilidade urbana. Rio de Janeiro: Jorge Zahar Ed., 2007. 
FUNARI, Pedro Paulo Abreu; PELEGRINI, Sandra de Cássia Araújo. Patrimônio histórico e cultural. Rio de Janeiro: Jorge Zahar Ed., 2009.

INSTITUTO DE PESQUISA E PLANEJAMENTO URBANO DE CURITIBA, IPPUC. Curitiba em Dados. Disponível em: $<$ http://curitibaemdados.ippuc.org.br/Curitiba_em_dados_Pesquisa.htm>. Acesso em: 15 ago. 2014.

JACOBS, Jane. Morte e vida de grandes cidades. São Paulo: Martins Fontes, 2000.

JEUDY, Henri-Pierre. Espelho das Cidades. Rio de Janeiro: Casa da Palavra, 2005.

LEITE, Rogerio Proença. Contra-usos da cidade: lugares e espaço público na experiência urbana contemporânea. Campinas, SP: Editora da Unicamp; Aracaju, SE: Editora UFS, 2007.

LERNER, Jaime. Acupuntura urbana. Rio de Janeiro: Record, 2005.

MARICATO, Ermínia. Brasil, cidades: alternativas para a crise urbana. Rio de Janeiro: Vozes, 2001.

MEYER, Regina Prosperi. O espaço da vida coletiva. In: ALMEIDA, Marco Antonio Ramos de; MEYER, Regina P. (Org.). Os centros das metrópoles: reflexões e propostas para a cidade democrática do século XXI. São Paulo: Editora Terceiro Nome, Viva o Centro, Imprensa Oficial do Estado, 2001.

PATRIMÔNIO CULTURAL. Paisagem urbana da Rua XV de Novembro. Disponível em: $<$ http://www.patrimoniocultural.pr.gov.br/modules/conteudo/conteudo.php?conteudo=62〉.

Acesso em: 24 maio 2014.

RIBEIRO, Luiz Cesar de Queiroz. Dos cortiços aos condomínios fechados: as formas de produção da moradia na cidade do Rio de Janeiro. Rio de Janeiro: Civilização Brasileira: IPPUR, UFRJ: FASE, 1997.

SILVA, Rodrigo da; OLIVEIRA, Carlos Eduardo França de; BORGES, Joacir Navarro. Memória da cidade: história e patrimônio urbano no Brasil. São Paulo: Conceito Humanidades, 2011.

ULTRAMARI, Clóvis et al. $O$ olho do inseto: ensaios sobre a cidade. Curitiba: Editora Champagnat, 2014.

Recebido em: 17/09/2014

Aprovado em: 20/11/2014 